\title{
THE BENEFITS OF USING SMALL SUPERVISOR-INITIATED GROUPS TO SUPERVISE MASTER'S RESEARCH
}

\section{S. M. O'Neil*}

e-mail: sumari.oneil@up.ac.za

\section{W. Schurink*}

e-mail: willem@schurink.co.za

\author{
K. Stanz* \\ e-mail: karel.stanz@up.ac.za
}

*Department of Human Resource Management

University of Pretoria

Pretoria, South Africa

\section{ABSTRACT}

This article is based on an autoethnographic study I carried out between 2004 and 2015 to explore the benefits of group supervision. I obtained my data from self-observations and self-reflections, documents and artefacts of my supervision practice, observations, and field notes on both the context and the students. I also collected external data from my (mostly master's) students through interactive interviews, informal conversations, e-mail exchanges and recordings of group supervision sessions. Most group supervision practices rely on highly structured faculty-wide implementation systems. My finding was that both student and supervisor benefitted significantly from group supervision even though the implementation was on a supervisor level. The benefits observed were enhanced when the group consisted of a small number of diverse students.

Keywords: autoethnography, coursework master's, group supervision, mini-dissertation, multivoiced supervision, postgraduate research supervision, qualitative inquiry

\section{INTRODUCTION}

Postgraduate research supervision is one of the core components of academic work. In light of the changing higher education environment in South Africa, with its increased teaching loads, drive for more research outputs, increased focus on enhancing the quality of teaching and learning, and increased administrative tasks, supervision has become challenging (Jansen, Herman and Pillay 2004; Olivier 2007). This article is based on an autoethnographic reflection searching for a more constructive supervision practice. More specifically, it describes the group supervision approach I used to improve my practice. 
Although the literature available on alternative forms of supervision is increasing, it remains in the minority, and where its practice is documented, it lacks detail and clear guidelines on how to implement it (Buttery, Richter and Filho 2005). Furthermore, most of the research focussing on group supervision practices uses structured, faculty-wide implementation mostly using student cohorts (De Lange, Pillay and Chikoko 2011). The group supervision practices described in this article are implemented on a supervisory level, and include a multivoiced approach (Samara 2006).

\section{METHODOLOGY}

Autoethnography is an approach to research and writing that involves systematically collecting, analysing and interpreting data about the self, the environment and possibly others (Ngunjiri, Hernandez and Chang 2010). My study focussed on my own experiences of supervision from 2004 to 2015, as well as the experiences of the students I had supervised during this time. The sources of data included both self-observations and self-reflections of my own lived experiences, the documents and artefacts of my supervision practice, observations, and field notes on both the context and the students. External data was also collected from my students by means of interactive interviews, informal conversations, e-mail exchanges and recordings of the group supervision sessions. Most of the student input came from my students enrolled for a coursework master's degree in Industrial and Organisational Psychology at the Department of Human Resource Management, where I am a lecturer. All of these students have to complete a mini-dissertation within 12 to 18 months after completing their structured coursework year.

\section{THE INADEQUACY OF THE ‘SOLO’ SUPERVISION STRUCTURE}

I started out supervising the only way I knew, that is, by way of a dyadic relationship between me as the supervisor and the student (also referred to as single, one-on-one or solo supervision). Although the dyadic model still provides highly personalised 'teaching' opportunities, it was developed and more appropriate in a time when there was less diversity between lecturers and students and also considerably lower workloads and less work intensity for academic staff (Grant 2003; Lee and Green 2009; Bitzer and Albertyn 2011). Students supervised in accordance with a dyadic model are motivated and well prepared and can complete their research over an extended period of time (Zhao 2001). Contrary to this finding, most of the students I supervise are not motivated to engage in research, seeing it as an obstacle in their way to registering as industrial psychologists. They also do not have long periods of time to 
spend on their research.

Between 2004 and 2007, I used only the one-on-one approach, and in this time personally experienced its many shortcomings (see Johnson, Lee and Green 2000; Buttery, Richter and Filho 2005; Dysthe, Samara and Westrheim 2006; Olivier 2007; Bitzer and Albertyn 2011). The most obvious shortcoming was the lack of providing social and emotional support to students, but perhaps this had less to do with the approach and more with my inability to provide this support. I had a tendency to take a functionalist approach, focussing on the technical aspects of the research (Lee 2008; Botha 2010). The move from a structured graduate course to an unstructured postgraduate course, as is the case in a master's coursework programme, increases a student's need for both structure and social interaction (Katz 1997). In addition, the significant change in the academic environment in terms of structure, expectation and approach to teaching and learning between the structured courses and the unstructured coursework programme at master's level (Anderson, Day and McLaughlin 2006; Ali and Kohun 2007) is exacerbated by the learnt dependence that students develop as a result of the highly structured teaching during the coursework and preceding years of studies (Morton and Worthley 1995; Olivier 2007; Sambrook, Stewart and Roberts 2008). In fact, I often experienced students as being overdependent.

\section{SEARCHING FOR ALTERNATIVE SUPERVISION METHODS}

At first I wanted to replace my one-on-one supervision practice with an alternative method altogether. However, even with its inherent shortcomings, I realised it still had worth (Bitzer and Albertyn 2011). In terms of the personal and individualist character of this practice, one of my students mentioned in a conversation that:

When I am alone with my supervisor I can say exactly what I feel, but I cannot always express myself equally freely in the company of the group (JaneD, Interview, April 2012).

Other students' comments echoed what Dysthe, Samara, and Westrheim (2006) and Donnelly and Fitzmaurice (2013) found in their research, that is, that individual supervision provided very specific advice and offered quality assurance to individual students. Consequently, I combined an individual and group approach as proposed by De Lange, Pillay, and Chikoko (2011) and Malfroy (2005). For Malfroy, however, individual supervision served as follow-up to group meetings. For me, the individual supervision was devoted to specific and detailed feedback on a specific student's work. This was the type of feedback that might not be directly related to the other students' work. It also served as a safety net for students so that they did not 
feel as though they were deprived of individual supervision. They always knew that they could come and see me individually. It is interesting, however, that as the group supervision increased in regularity the need for individual student sessions decreased.

In my search for guidelines on how to implement a group approach, I explored the literature and came across a number of studies that reported on the implementation of group practices (Zuber-Skerritt and Knight 1987; Conrad and Phillips 1995; Hortsmanshof and Conrad 2003; Grevholm, Persson and Wall 2005; Anderson, Day and McLaughlin 2006; Dysthe, Samara and Westrheim 2006; Samara 2006; Manathunga and Gozée 2007; Wisker, Robinson and Shacham 2007; Neville 2008; Parker 2009; McFarlane 2010; Watts 2010; De Lange, Pillay and Chikoko 2011; Donnelly and Fitzmaurice 2013). Many of these group approaches described were implemented on faculty level and involved highly structured cohort groups (Zuber-Skerritt and Knight 1987; Hortsmanshof and Conrad 2004; Grevholm, Persson and Wall 2005; Dysthe, Samara and Westrheim 2006; Wisker, Robinson and Shacham 2007; De Lange, Pillay and Chikoko 2011). The organisation of a faculty- or department-wide, curriculum-based approach was not an option at the time. Furthermore, owing to institutional requirements a committee model involving joint supervision (also referred to as panel supervision or multiplicity) was not an option for master's students (Dysthe, Samara and Westrheim 2006; Samara 2006; Van Biljon and De Kock 2011).

Based on the above, I implemented a group approach that took account of the work of Manathunga and Gozée (2007), Neville (2008), McFarlane (2010), and also Conrad and Phillips (1995). My groups were and varied between three and eight students at a time. As the students' topics or the methodology followed did not overlap much, these groups can be described as 'multivoiced' (Dysthe, Samara and Westrheim 2006). As in the case of the groups described by Neville (2008), our group meetings revolved around spontaneous discussions regarding student progress and problems encountered, and information and resource sharing occurred spontaneously among group members. The meetings had little structure and could rather be described as informal conversations (Manathunga and Gozée (2007). The group meetings were also similar to those reported on by Hortsmanshof and Conrad (2003) in that each group session was unique and evolved from the students' experiences that they shared during the session. I would begin a session by asking the students if there was anything specific they would like us to talk about. Most of the time, the students did not select any specific topic beforehand. The themes of the discussion emerged during the sessions. Most sessions involved sharing of what had been learned and the feelings students were dealing with.

I would start each session with a welcoming, and if there were any new students, I would 
introduce them to the group. Then we would start a round-robin discussion, giving every student the chance to say what they were busy with in their dissertations, how they had progressed in the last couple of weeks, what they struggled with and what they planned to do in the next couple of weeks. This method ensures that all the members in the group participate.

Group discussions are of critical value in the development of dissertations (Botha 2010). In itself, a group discussion serves as a catalyst for the creation of new ideas and understandings (Dysthe, Samara and Westrheim 2006). During the discussion, I tried not to lead the conversation. I wanted the students to share their own ideas amongst each other first, after which I would share my thoughts. Unless it seemed as though the students did not want to share, I would ask questions or share my ideas to get the conversation going. I found that my approach was similar to that of Hortsmanshof and Conrad (2003) in that the discussion in my group was facilitated by the supervisor (me) posing questions with regard to the topic discussed in the specific session. This ensures that I, as a supervisor, still have the central position, which is crucial to the success of the group for supervision purposes, as pointed out by Dysthe, Samara, and Westrheim (2006). Even though I facilitated the conversation, the students' input was equal in importance to my own (Malfroy 2005).

Owing to the diversity of the students taking part in my group sessions, it was difficult to replicate a structured workshop approach, although this was not for lack of trying. During 2011 and 2012, I did actually implement a more structured group-session approach, where I would discuss each chapter of a dissertation on a scheduled day. I would then discuss the contents and answer questions with regard to that chapter, and I allowed students who wanted to write their chapters in my presence to do so for half a day. I used this opportunity to give input on their writing if they needed it. The comments of the students indicated that these sessions helped them a lot:

I really regret this as I feel the workshops are very beneficial to me and help me a lot (Ester, in an e-mail, 2012).

These sessions (the writing workshops) made the biggest difference; the problem was just that I could not attend all of them [owing to work responsibilities] (Parishna, Interview, April 2012)

However, many of the students did not attend the writing workshops, the main reason being that their dissertations had not progressed to the chapter under discussion at a workshop so they felt they would not derive any benefit from such a discussion:

Last year I thought the chapter-by-chapter discussions were very cool. I attended one of those discussions, but since I was only at the proposal part I could not get a lot from it. However, I would love to take part in something like that (JaneD, e-mail reflection, April 2012). 
Another factor that made me decide against the type of group described above was the fact that it limited interaction amongst the students themselves. In the writing workshops, although the students spontaneously discussed the work amongst themselves and shared ideas, it seemed that the formalisation of the sessions put me 'as lecturer' in charge of providing information. For this reason and because some students did not attend the workshops as they felt they wasted their time (either because they had already completed the relevant section or had not started with it), I decided to abandon these sessions.

Contrary to the finding of Malfroy (2005), I found that with little structure students' immediate needs were taken care of. As one of the students mentioned:

I would have hated structure. It focusses only on one thing, because what if you have a persistent issue. The unstructured way is better, because it is more relaxed (Maria, Interview, October 2014).

When there was less structure the students spontaneously discussed their good and bad experiences with their mini-dissertations; in the more structured workshop sessions they did not do this.

With a lack of structure, however, there was some risk of the group focussing only on the negative experiences of students:

[On the negative side], one goes away [from the group discussion] dragging your feet, and you feel that it is okay to drag your feet as far as your work is concerned because everyone is doing it and they are struggling to make progress. At times it feels as though it is the norm. I would have preferred it to be a more positive discussion rather than a moaning session (Claudia, e-mail reflection, October 2014).

Other sessions felt like long moaning sessions without reaching anything in the session. Moaning can be quite pleasurable at times and may even be necessary, but sometimes we had too much moaning and too few answers. During such sessions I felt that I was learning nothing and that they were a waste of time. My suggestion for the future would be that every session must contain a learning activity. The talking and moaning can still happen (it is necessary) (Christine, e-mail reflection, October 2014).

The above comments point to the importance of finding a balance between set learning activities and informal reflective discussions. In addition, the informal learning discussions should focus not only on the challenges but also on overcoming the challenges (Baird 1997). The inherent diversity of the group added value to the group sessions:

It helped me see my dissertation differently [in a different perspective]. ... It is actually valuable to have people at different stages of the research. It helps you reflect back with those that have just started and it helps you see your current situation and it helps you with the present when people 
provide you with solutions and also to look forward when someone is discussing their experiences and they are close to handing in (Maria, Interview, October 2014).

Baird (1997) also mentions this point when he says that students at different levels of the research process mingle to share information about the process and the psychological changes it would engender. In this way they could encourage one another to cope with the adversities of the process. More advanced students also modelled the behaviour strategies and approaches the less advanced students would need to master or, at other times, modelled behaviour that later students did not want to copy:

It was quite depressing to hear that someone had been busy for six years with her thesis. It awakens a fear in you that it may happen to you too, but it also motivated you to realise that the longer you are going to leave it the longer it will take you to complete it (Herman, Interview, October 2014).

Dysthe, Samara, and Westrheim (2006) concur when they say that it is important to have people from different research traditions in the same group to establish different voices, multiple perspectives and critical thinking. The diversity of methods the students used was an advantage to the group sessions:

It opens your mind; you start seeing things from a different perspective. Even though their research is different to yours, that can still provide solutions for your research because you actually are forced to look at something from a different angle (Maria, Interview, October 2014).

During the sessions, everyone would get a turn in a round-robin fashion to reflect on where he or she was currently in the research process, what problems they were experiencing, and what positive aspects they had experienced. At the end of each session, everyone would also get a turn to say what he or she would do next in order to progress. On reflection I realise that the sessions have a definite reflective perspective, and the process itself relates to the cycle of reflection developed by Kolb (1984) (see Figure 1).

From my point of view, each get-together was like a public reflection circle (Reilly and Bramwell 2007). The students reflected on what had transpired recently, and what had been planned, observed and achieved in practice. Such reflection illuminates what has been experienced by both the self and others, which provides direction for future actions. Reflecting in a group places each student in a position of having to clarify their own thoughts 


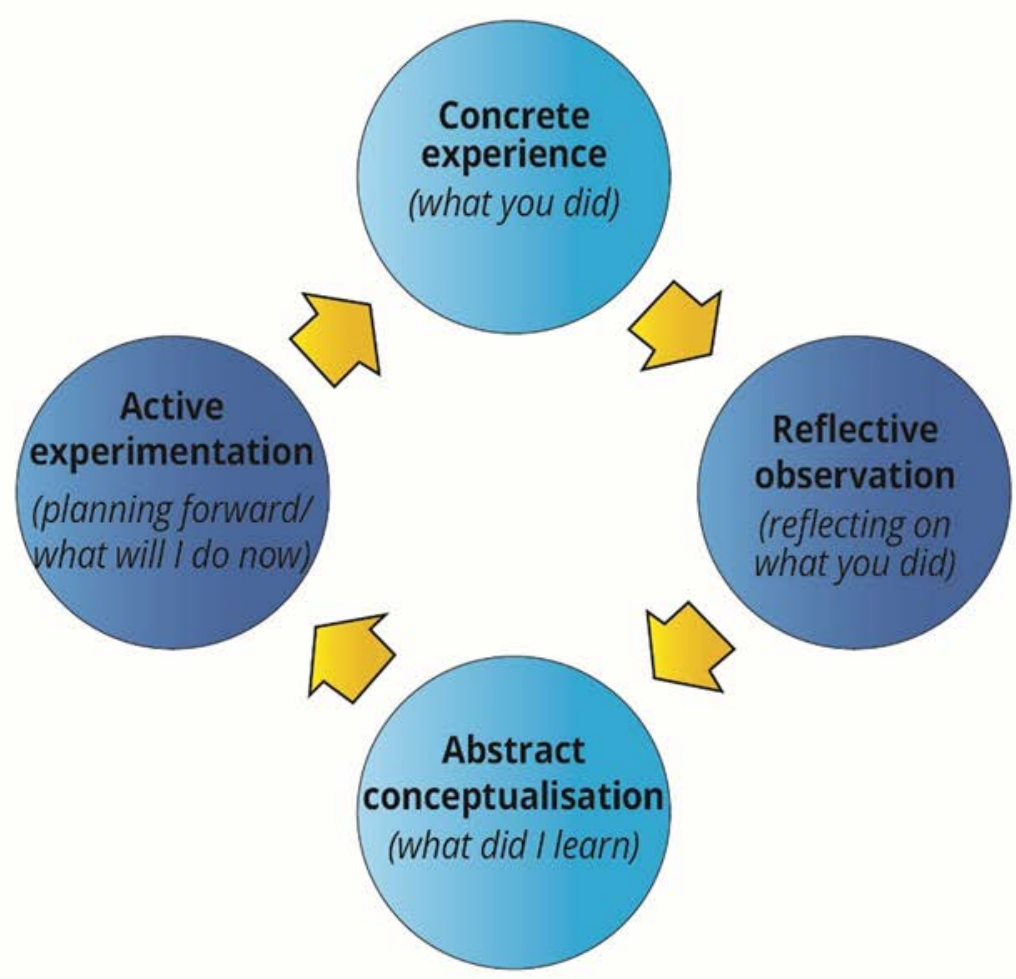

Figure 1: Kolb's (1984) experiential learning cycle as applied to my group discussions

and decision processes; if they articulate their reasoning and it is validated by the group it also becomes easier to write. By periodically stepping back from an experience and reflecting on it while being listened to by an audience of others who share a similar experience, a novice is able to make explicit meaning of actions or feelings for the self. In the case of my groups the students shared their experiences of working on their research.

The public nature of the group and the verbalisation and discussion of thoughts are central to the development of metacognition (Reilly and Bramwell 2007). Through public reflection the internal processes are made transparent and are verbalised. By stepping back from activities and feelings from time to time, the meanings of these activities and feelings are shared with others who had the same experience and in this way they are made sense of. This in turn forms the basis of future actions. The actions which build metacognition are clearly illustrated in the reflections of my students:

When you hear someone else talk, you relate it back to your own research ... I don't have to think about it hypothetically, it [thinking about your own research] has happened in the past. It puts the focus on your research. You have to think about it and you have to take in the emotions that come with it. (Maria, Interview, October 2014). 
Samara (2006) and Wisker et al. (2004) also mention that group supervision practices develop students’ metacognitive skills. In their assessments, students developed metaknowledge of their own research and writing processes. Although the students in my groups do not consciously take note of their metacognitive development, and this development is never measured, the reflection on action will develop students' meta-cognitive skills. Public reflection such as that voiced in a supervisory group, encourages making transparent the internal processes and verbalisation of student experiences (Reilly and Bramwell 2007).

Wisker et al. (2004) refer to a factor of metacognition that is extremely important in research learning. Research learning denotes the learning that takes place during engagement with research activities (Jansen, Herman and Pillay 2004). According to Wisker et al. (2004), the act of engaging students in sharing their stories of how and what they have learned of research, and the processes and approaches they have engaged in, aids metalearning in that it enables both a clear focus on the research and articulation between its parts 'as well as articulation of its arguments and achievement, using the metalanguage of research itself' (Wisker et al. 2004, 477). The latter is one of the most difficult obstacles students face when they engage in research. Through talking about their research, students acquire an ability to articulate and defend the reasons behind the choices they make during the research process (e.g. selection of theories, methodology and methods). And this is the reason why it then becomes easier to write.

\section{PRACTICAL ARRANGEMENTS: HOW LONG, WHERE, AND HOW OFTEN?}

Since all the students I supervise work full-time, the groups come together for between 90 and 120 minutes in the evening after work (18:00). Regardless of varying the times for these sessions there was always a student or two who could not attend from time to time owing to work responsibilities, or who could not be on time. Nevertheless, (beyond my expectations) all the students actually went to the trouble of attending these group sessions:

I never had a pain with attending group sessions. I enjoyed it and looked forward to it. It was something else (Herman, Interview, October 2014).

I like the group sessions. I really, really like it! ... If there were more group sessions, like they are actually like very valuable. They are actually like worth having and worth setting that time aside for an hour or more (Maria, Interview, October 2014).

If you just set aside the time and get here [to the group session], it really adds value (Hanna, Session, February 2010).

Although Conrad and Phillips (1995) recommend that meetings should be held every two to 
four weeks, I find that meetings held every six to eight weeks are less burdensome for working students. If meetings are scheduled further apart students have more time to work on their dissertations between sessions. Meetings at shorter intervals would be more suitable for fulltime students who are on campus.

Over the years I used different locations for holding the group sessions, from coffee shops (on and off campus) and the library to other locations on campus. Most of the students agreed that the practical arrangements to go off campus to a coffee shop were cumbersome. It was also noisy in most public places, which made it difficult to concentrate.

I remember that we met at Wimpy's once. I did not enjoy that. I thought it was too informal, and I felt that everyone was distracted. I think a quiet academic environment is better (Chris, Reflection 2012).

Meetings should be held in a quiet space that affords the opportunity to have informal discussions, yet lends itself to giving presentations using audio-visual equipment if required.

\section{THE BENEFITS OF MY SUPERVISION GROUPS}

In my analysis of the student feedback over the years 14 broad themes emerged (see Table 1). To compress the themes into meaningful categories, I used the framework developed by LotzSisitka et al. (2010). These authors highlight four benefits of working within a community of practice: 1) relating to others work, 2) adding structure to ideas, 3) taking responsibility and 4) affording opportunities to explain and express (see Figure 2). The benefits depicted in Figure 2 are related in that they can affect each other.

Table 1: Benefits of the group sessions represented by 14 themes

\begin{tabular}{|ll|}
\hline 1. & Active peer support \\
\hline 2. & Collaborative knowledge sharing \\
\hline 3. & Decreasing isolation of students \\
\hline 4. & Increasing motivation of students \\
\hline 5. & Increasing individual understanding \\
\hline 6. & Building student confidence \\
\hline 7. & Creating an effective learning opportunity \\
\hline 8. & Expanding each other's range of interpretation \\
\hline 9. & Facilitating new initiatives and ideas \\
\hline 10. & Providing encouragement \\
\hline 11. & Providing guidance and technical support \\
\hline 12. & Providing a frame for time management and prioritisation of \\
\hline 13. & Sharing and gathering materials \\
\hline 14. & Giving and receiving emotional support \\
\hline
\end{tabular}




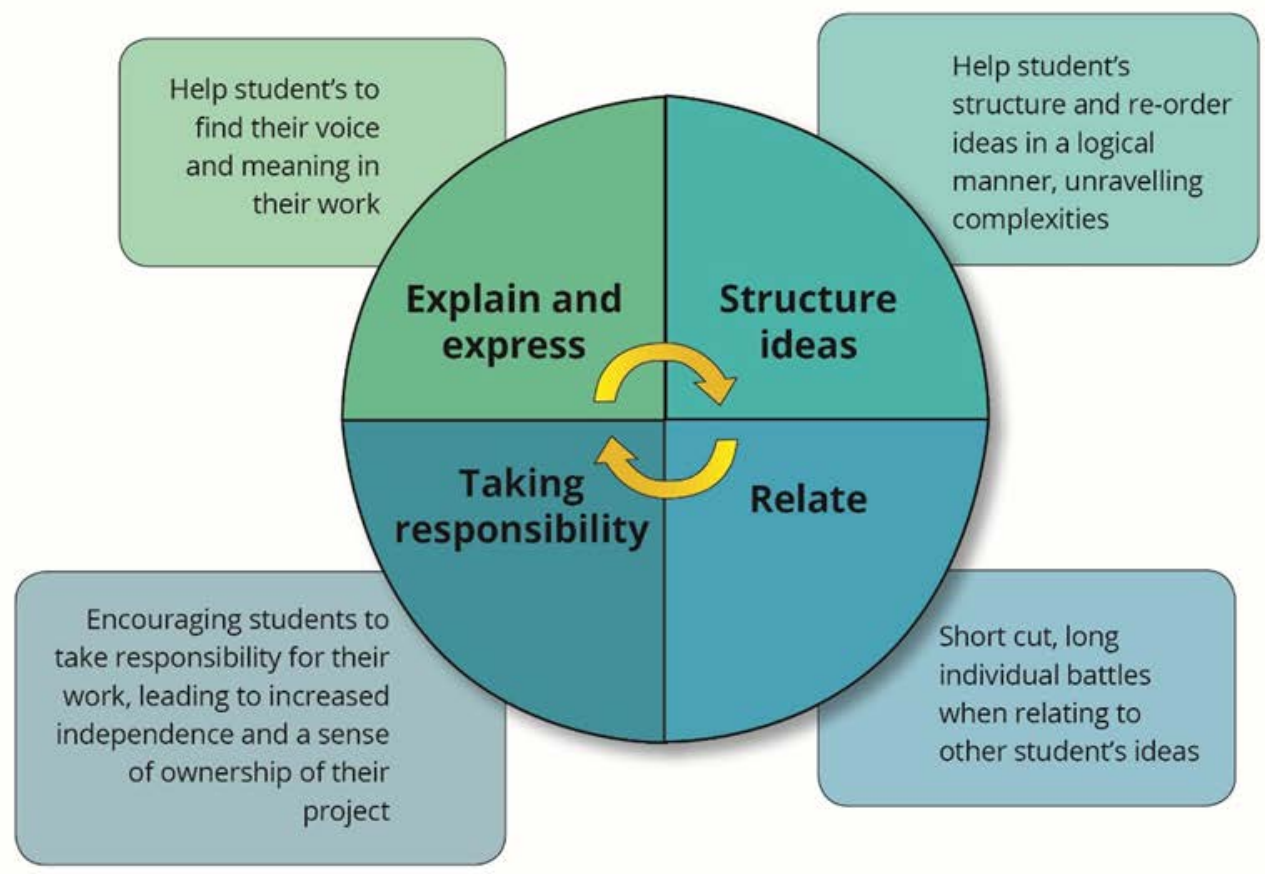

Figure 2: Benefits of group supervision Source: Adapted from Lotz-Sisitka et al. 2010

\section{Relating to each other's work}

To relate to someone else's journey helps students overcome their challenges and, as LotzSistika et al. (2010) note, helps them create short cuts to tackling individual battles that would normally take much longer. This was evident in my students' reflections on the group sessions:

It was not necessarily the contents but more importantly to keep going or to focus on your work or stuff like that or how to approach it that helped a lot (JaneD, Interview, April 2012).

People can provide solutions to the problems you're facing with the research. I know that happened to me. I was discussing my research and my methodology ... they [the group] actually said: 'hey, why don't you do it like this'. So you actually help each other concerning your research specifically. ... Remember, Christa was saying, don't waste too much time with the editing. It was something that you can work on later and the editor helps with that ... so I've taken note of that in my research, and it helps a lot (Maria, Interview, October 2014).

Yes, I liked Ester's suggestion that you simply have to write down something even though you will have to panel beat it later on. I think it will reduce frustration levels because I will have something at least and something is better than nothing. I underestimated the work on my thesis and I will have to give lot of thought to milestones (Christine, e-mail reflection, 2010)

Because a group setting provides the opportunity for collaborative knowledge sharing (Malfroy 2005) it also helps to lessen students’ uncertainty and confusion. In sharing knowledge, there 
is also research capacity development (Malfroy 2005) between the group members (including the supervisor). This happened often in the group sessions where students showed each other methods of data analysis or writing. In this way, the students gained insight through their own contributions, as well as through the interactions among the group members. Through these processes I could recognise the benefit of enhancing the acculturation process and help new students establish a research identity while also focussing on skills development as mentioned by Dysthe, Samara, and Westrheim (2006). I could also clearly recognise the instructional benefits of the group setting (Dysthe, Samara and Westrheim 2006).

\section{Structuring ideas}

Through discussion students have to present their ideas. Lotz-Sisitka et al. (2010) refer to this as the structuring of ideas when students formally present their work. In my group sessions, students mostly presented their work in informal discussions. When they did, however, formally present their ideas in preparation for a conference, it helped them tremendously to arrange their arguments logically. I have found that a great deal more happens in the group than merely discovering the best structure for an argument. It is also about understanding things from new perspectives and even discovering new ideas, even in the informal discussions. By sharing their experiences, students are accessing 'places' they have not yet been and therefore expand each other's range of interpretive options (Dysthe, Samara and Westrheim 2006). The group discussions give rise to new ideas and new perspectives on old ideas (Samara 2006). These processes increase in a diverse group setting since students talk from diverse perspectives. By looking through different perceptual and theoretical lenses in diverse groups especially, cognitive structures and knowledge connections are elaborated on. I agree with Dysthe, Samara, and Westrheim (2006) that group interaction may provide new initiatives and ideas and that it is usually the most productive aspect of supervisory groups. Talking about and relating to other's discussions help unravel the complexities of your own research. This is very clear in the feedback I received from students over the years:

When you start talking about a problem you often come to new ideas and perceptions about solving the problem. Quite often the solution is something I would never have thought of on my own. The session definitely gives you some perspective (JaneD, Interview, 2011).

You might be hitting a brick wall and then it [the group] provides new ways of thinking because someone said something or someone provided a suggestion. Then you actually want to work on it because you feel you found a solution to your problem, because usually the obstacles are like brick walls and prevent you from working but once you got a solution you are motivated and you want to work on it. That has really happened to me. We would have a session, and I would go home and I would work on my dissertation (Maria, Interview, October 2014). 
The diversity of the group enhanced the knowledge sharing process:

It [the diversity] made a contribution since people advise you about parts that they have completed and which you still have to do. They have gone through it and can tell you what works and what does not work.

[T] started with their studies and who are still very confused] can learn a great deal from students who are almost finished. The senior student can help with that last push at the end which can be a very frustrating part of the study. It is nice to see that you can finish and that it is possible even if it does not seem like it. Students who have completed their studies have a little industrial knowledge and experience that are necessary to give the study some spin, i.e. make it relevant to the industry (Christine, e-mail reflections, 24 Oct 2014).

\section{Explaining and expressing}

Being part of a group forces students to verbalise and explain what they are doing in their research.

When you're in a group you feel like you have to be there to contribute .... It forces you to get tougher and talk about it [your research] (Parishna, Interview, April 2012).

Talk is the fundamental vehicle that connects reading and writing for building meaning (Aitchison 2009, 907). When the one student shares his or her research, the other students have to respond. 'Giving and receiving feedback in public, in particular, seem to have been empowering and forming experiences' (Dysthe, Samara and Westrheim 2006, 312). Peer support from fellow students who can provide encouragement and guidance which in turn helps address stressful situations is very valuable (Protivnak and Foss 2009). Although my students gave feedback to each other in conversations, the occasions when students presented their research provided formalised opportunities for expression, explanation and feedback.

\section{Taking responsibility}

For Lotz-Sistika et al. (2010, 144), taking responsibility implies that the student will be encouraged to 'take responsibility for developing their own ideas without waiting for the supervisor to point out the next step'. I believe that this also indicates that the students are mobilised through the group activities to work on their dissertations and thus rely less on the supervisor for specific direction. The students indicated that they were motivated and mobilised to work on their research after our group meetings:

The two most productive sessions were right after group sessions. The meetings helped a lot to 
light a fire under me (Herman, Interview, October 2014).

The motivation to work also has something to do with the fact that the students mingle with their peers and get a sense of how important it is to complete the dissertation work. This implies that the group exposure assists students with time management and the prioritisation of tasks (Conrad and Phillips 1995).

I realised during the group meeting that it does not matter where you are in your life, it is never going to be a breeze. You will have to sit down and put hours into your work, since that is going to determine what you get out. It is good to hear the opinions of everyone and to learn from their faults. The session helped a lot. It brought you back to reality (Claudia, e-mail reflection, 19 March 2011).

\section{Benefits additional to those identified by Lotz-Sisitka et al.}

Other benefits that do not fall into the categories of the framework of Lotz-Sisitka et al. (2010) emanated from the students' evaluation of group supervision. A factor that came to the fore very strongly was the decrease in isolation that the students experienced. This was something also mentioned by other scholars (Dysthe, Samara and Westrheim 2006; McIlveen et al. 2006; Samara 2006; Wisker, Robinson, and Shacham 2007; Bitzer and Albertyn 2011; De Lange, Pillay, and Chikoko 2011).

I could differentiate the reduction of isolation on three levels: 1) a physical level through sharing of resources such as literature lists, as well as meeting each other in person, 2) an emotional level, where the group would support and motivate each other and engender a sense of belonging, and 3) a cognitive level, where the individual student found someone with whom to share their thoughts and where academic discussion could take place.

For me, the cognitive level has an important acculturation function, where the group allows an 'important arena for acculturation into the thinking and discourse of the discipline' (Dysthe, Samara and Westrheim 2006, 307). The cognitive level falls into the level of benefits, as highlighted in the framework of Lotz-Sisitka et al. (2010). However, the physical and emotional levels are not included in their framework and, therefore, I add them here.

On a physical level, the group support networks formed among the students extended outside the physical group session (see also Conrad and Phillips 1995). This was evident in the way the group spontaneously shared resources.

When I see something I may think that there are things that are relevant to another student's studies ... we share articles and resources. It makes everything easier ... (JaneD, Interview, April 2012).

Although I found it difficult in my solo supervision practice to support students emotionally 
and socially, I realise that the emotional aspects of completing the dissertation are crucial to completing their learning journey (Meyer and Land 2003; Meyer 2007). Dysthe, Samara, and Westrheim (2006) mention in their study how the group provides a safe environment where the role of emotions in the research process can be discussed. To me it was evident that the group provided an acceptable place for discussion in particular because there were others who shared their emotions. These discussions also served to motivate students. The group participation made the students feel that their own individual experiences were not unique, and made them feel fired up and enthusiastic to continue with the processes.

I think it gives you the perspective that you are not alone, and someone else is going through it as well. And if they can do it, so can I. That's very helpful. ... When we actually got together, those sessions ..., if for nothing else [they built] morale and motivation. It's amazing! (Parishna, Interview, April 2012).

I must say, the group sessions help a lot with moral support. I have lost eight hours of yesterday's [Thursday's] work. For some reason or other [I] did not save the work before I switched off my computer last night. I think if I didn't attend the group session on Monday I would have been in a much worse emotional space today (Hanna, e-mail, 3 March 2010).

It motivated me when I saw that other people were also uncertain, that they were also making mistakes and I felt less like the village idiot. It is a lonely journey. To hear that others are feeling like I do and experience things like I do bring a collective feeling of protection to me (Christine, e-mail reflection on group, 24 October 2014).

Social isolation is one of the major reasons why students do not complete their research successfully (Jansen, Herman and Pillay 2004; Ali and Kohun 2007; Bitzer and Albertyn 2011), and it has been identified as one of the four risk factors associated with non-completion of postgraduate students' work in South Africa (Academy of Science of South Africa 2010). The establishment of social relationships contributes to the capacity of the individual student to work independently and it also increases the student's well-being (Ali and Kohun 2007). On the one hand the student's well-being is increased by the group processes through building his or her self-confidence and research self-efficacy (Ahern and Manatunga 2004), as they realise through discussion that they are not abnormal and insane to feel the way they do about their research. On the other hand, through knowledge sharing they become aware of what they know. The socially isolated student will not have a framework of comparison for his own work and progress (Ali and Kohun 2007).

Meyer and Land (2003) note that not understanding or knowing is not only cognitive, but has an emotional and social component attached to it. Peer interaction is therefore actually one of the strategies that help students cross the threshold concepts (Kiley 2009). The conversations help the students recognise when they are stuck, and how being stuck has manifested in their 
inability to progress. The group interaction helps the student realise that it is not uncommon to be in such a position, and the conversations even give rise to ideas on how to become unstuck.

\section{Towards a more comprehensive and complete supervision practice}

The benefits of a group that have been discussed thus far have a strong support component, enabling students to work on their research. This support function is an aspect that was lacking in my one-on-one supervision practice. The addition of the group sessions therefore introduced a good balance to my supervision practice. Where originally I focussed more on the functional aspects of supervision, referred to by Anderson, Day, and McLaughlin (2006) as a shaping function relating to the quality of the dissertation and the theoretical and discipline-orientated assistance (Dysthe, Samara and Westrheim 2006), the addition of the group sessions provided better support on a social and emotional level as a group session is a better place for exchanging experiences, letting out frustrations and talking about problems of a personal and researchrelated nature (Dysthe, Samara and Westrheim 2006). Support on a social and emotional level, according to Anderson, Day, and McLaughlin (2006), adds more to a support function in supervision (see Figure 3). The combination of group and individual supervision in my supervision practice balanced the duality between shaping and giving support. As the students indicated:

Single supervised students do not have the luxuries that we have. They don't know what they are missing out on. It's limiting because anyone else [peers] can shed some light on their (the other students') experiences. They don't get to see things from a different perspective (Maria, Interview, October 2014).

It was good not only to speak to my supervisor about my thesis but also to hear what others are doing. The fact that not you and I were talking about my thesis added to learning and experience. There is a place for both group and individual supervision. It is the student's responsibility to request individual supervision. The group sessions were worth a great deal (Herman, Interview, October 2014).

Overall, as a supervisor I feel that using the group method in combination with individual supervision strengthens my practice. It fills the hole created by my inability to provide social support and emotional support to the students as it creates an opportunity for peer support that I cannot provide (Samara 2006). Other than that it also builds my own research capacity (Malfroy 2005) as I learn also from the students and the strategies that they share to overcome 


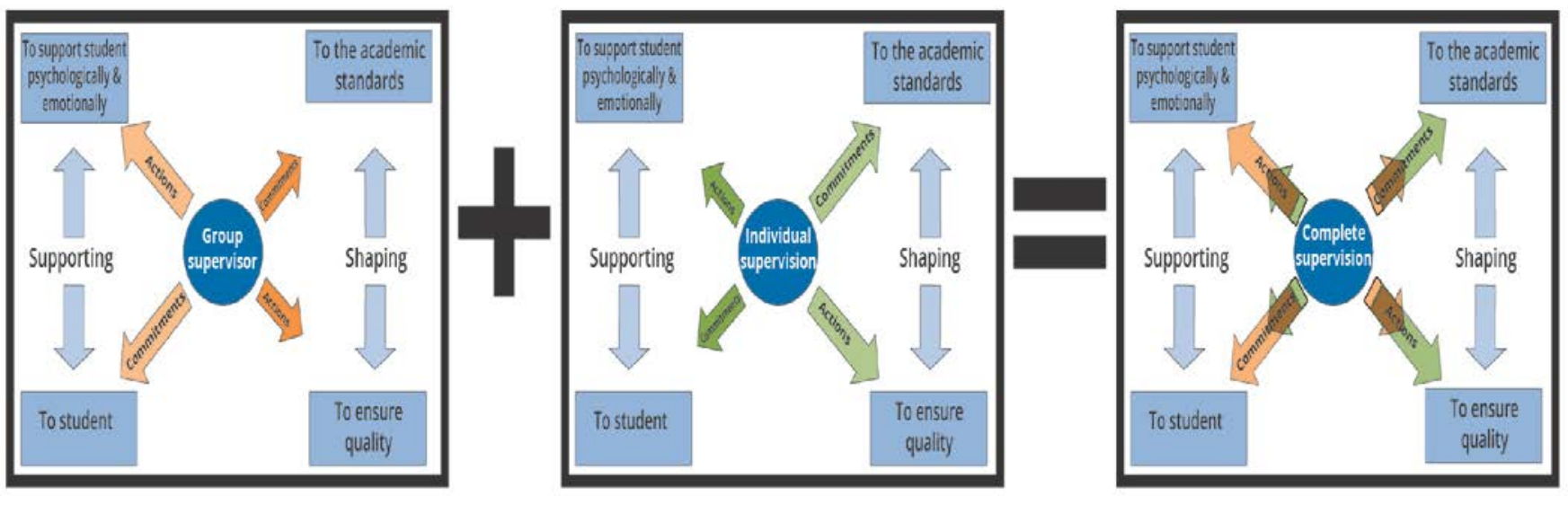

Figure 3: Balancing the duality of supporting and shaping through a combination of group and individual supervision (adapted from Anderson, Day and McLaughlin (2006))

challenges while conducting their research and writing their dissertations. In this sense, it assists me not only to become a better supervisor but also a better researcher.

Similar to the finding of De Lange, Pillay, and Chikoko (2011) that the cohort group of $\mathrm{PhD}$ students could expand the individual supervision, the evidence from all the information provided in this article points to the finding that the inclusion of group sessions for my own supervision students expanded supervision in the same way to include elements of all of the supervision approaches suggested by Lee (2008). Although my own personal input is still the strongest on the functional level, the group definitely has a role to play in the students' directing and management of their projects, and where inputs are given specifically on the research skills level. The group participation is in itself a form of enculturation, while the emotional and social support that is provided brings about emancipation. Furthermore, the student-centred nature of the group sessions introduces relationship building into the supervisory practice. Through the discussions, the students' critical thinking and reflection on their own and other's research are also illustrated.

\section{WHAT MY GROUPS DID NOT PROVIDE}

Peer mentoring, as mentioned by Conrad and Phillips (1995), where students would read each other's chapters, did not take place in my groups. It might have been easier to involve the students in reading activities if they had been full-time students. It is the lack of time that hinders the students from getting involved in each other's work on that level; they scarcely have time to work on their own dissertations, let alone to look at someone else's.

In earlier sessions, I experimented with sending chapters to the group to read before we got together. However, the students did not react to my requests. Although Dysthe, Samara, and 
Westrheim (2006) blame the individualistic nature of research learning for the lack of participation, the students in my groups also did not have time to read someone else's work critically as it would have taken time away from their focus on their own writing.

Owing to the lack of time and the pressure on students to complete quickly despite their full-time work and family obligations, I stopped pushing for peer mentorship and involvement on the level of reading. I then tried to take my own editing notes on students' chapters to the group sessions for discussion, but I felt that it hampered their natural involvement and spontaneous discussion and turned a group session into a lecture. Because the students were not at the same place in their studies, it also only benefitted a few. I still maintain that such a system would be extremely beneficial, however. The one student that did actually take the time to read other students’ chapters and my editing comments said that she learnt a lot from it:

At a time, you sent chapters of other students to us to peruse before the session and then make suggestions to the writer during the session. That session added a lot of value to me. I did not receive many suggestions but I received very good ideas of how to carry on by looking at other chapters. It gave me new ideas and perspective. In particular it helped me with my literature study which was giving me trouble (Christine, e-mail reflection, 24 October 2014).

Owing to the benefit it provides, I will in future use shorter excerpts from students' dissertations to read during sessions. This would provide a definite learning objective for each session, whilst also providing opportunities for active critical reading and feedback. As one student mentioned, these formalised parts of the group session should only be part of it. The rest of the session will therefore be made up of the informal reflective component that I am using currently.

\section{IN CONCLUSION}

Most group approaches presented in the literature use formalised and structured approaches which include formal curricula and departmental and/or faculty-wide implementation plans. These models of group supervision often include large numbers of students and the involvement of other supervisors. In this article, I have described implemented groups that involve only my own students. It is clear from this study that groups need not be implemented at a higher level or be more complicated and include wider implementation. Small groups, in which one supervisor's students get together to discuss their research journeys informally and critically, already harbour the positive effects of group practices.

\section{REFERENCES}

Academy of Science of South Africa. 2010. The PhD study: An evidence-based study on How to meet the demands for high-level skills in an emerging economy. Pretoria, South Africa: HSRC. 
www.hsrc.ac.za/en/research-data/ktree-doc/6367

Ahern, K. and C. Manathunga. 2004. Clutch-starting stalled research students. Innovative Higher Education 28(4).

Aitchison, C. 2009. Writing groups for doctoral education. Studies in Higher Education 34(8): 905-916. doi: 10.1080/03075070902785580.

Ali, A. and F. Kohun. 2007. Dealing with social isolation to minimize doctoral attrition: A four stage framework. International Journal of Doctoral Studies 2.

Anderson, C., K. Day and P. McLaughlin. 2006. Mastering the dissertation: Lecturers' representations of the purposes and processes of Master's level dissertation supervision. Studies in Higher Education 31(2): 149-168. doi: 10.1080/03075070600572017.

ASSaf see Academy of Science of South Africa.

Baird, L. L. 1997. Completing the dissertation: Theory, research, and practice. New Directions in Higher Education 99: 99-105.

Bitzer, E. and R. M. Albertyn. 2011. Alternative approaches to postgraduate supervision: A planning tool to facilitate supervisory processes. South African Journal of Higher Education 25(5): 874888.

Botha, N. 2010. Practices in post-graduate research supervision: From apprentice to scholar. Acta Academica Supplementum 1: 57-74.

Buttery, E. A., E. M. Richter and W. L. Filho. 2005. An overview of the elements that influence efficiency in post-graduate supervisory practice arrangements. International Journal of Education Management 19(1): 7-26. doi: 10.1180/09513540510574920.

Conrad, L. and E. M. Phillips. 1995. From isolation to collaboration: A positive change for postgraduate women? Higher Education 30(3): 313-322.

De Lange, N., G. Pillay, and V. Chikoko. 2011. Doctoral learning: A case for a cohort model of supervision and support. South African Journal of Education 31: 15-30.

Donnelly, R. and M. Fitzmaurice. 2013. Development of a model for blended postgraduate research supervision in Irish higher education. In Emerging issues in Higher Education III: From capacity building to sustainability, ed. C. O’Farrell and A. Farrell. Dublin: Educational Developers in Ireland Network (EDIN).

Dysthe, O., A. Samara and K. Westrheim. 2006. Multivoiced supervision of Master's students: A case of study of alternative supervision practices in higher education. Studies in Higher Education 31(3): 299-318. doi: 10.1080/03075070600680562.

Grant, B. 2003. Mapping the pleasures and risks of supervision. Discourse: Studies in the Cultural Politics of Education 24(2): 175-190. doi: 10.1080/0159630032000110720.

Grevholm, B., L. Persson and P. Wall. 2005. A dynamic model for education of doctoral students and guidance of supervisors in research groups. Educational Studies in Mathematics 60: 173-179. doi: 10.1007/s10649-005-4497-2.

Hortsmanshof, L. and L. Conrad. 2003. Postgraduate Peer Support Programme: Enhancing community. In Learning for an unknown future: Proceedings of the 2003 Annual International Conference of the Higher Education Research and Development Society of Australasia (HERDSA), edited by C. Bond, and P. Bright. Christchurch, New Zealand, 6-9 July, HERDSA, Milperra, NSW. ISBN: 0908557558.

Jansen, J., C. Herman and V. Pillay. 2004. Research learning. Journal of Education 34: 79-102.

Johnson, L., A. Lee and B. Green. 2000. The PhD and the autonomous self: Gender, rationality and postgraduate pedagogy. Studies in Higher Education 25 (2): 135-147.

Katz, E. L. 1997. Key players in the dissertation process. New Directions for Higher Education 99.

Kiley, M. 2009. Identifying threshold concepts and proposing strategies to support doctoral candidates. Innovations in Education and Teaching International 46(3): 293-304. doi: 


\section{$10.1080 / 1470329090306900$}

Kolb, D. 1984. Experiential learning: Experience as the source of learning and development. Upper Saddle River, New Jersey: Prentice Hall.

Lee, A. 2008. How are doctoral students supervised? Concepts of doctoral research supervision. Studies in Higher Education 33(3): 267-281.

Lee, A. and B. Green. 2009. Supervision as metaphor. Studies in Higher Education 34(6): 615-630. doi: $10.1080 / 03075070802597168$.

Lotz-Sisitka, H., K. Ellery, L. Olvitt, I. Schudel and R. O’Donoghue. 2010. Cultivating a scholarly community of practice. Acta Academica Supplementum 1: 130-150.

Malfroy, J. 2005. Doctoral supervision, workplace research and changing pedagogic practices. Higher Education Research and Development 24(2): 165-178. doi: 10.1080/07294360500062961.

Manathunga, C. and J. Goozée. 2007. Challenging the dual assumption of the 'always/already' autonomous student and effective supervisor. Teaching in Higher Education 12(3): 309-322. doi: 10.1080/13562510701278658.

McFarlane, J. 2010. Group supervision: An appropriate way to guide postgraduate students? Acta Academica 42(4): 148-170.

Mcllveen, P. J., M. R. George, S. L. Voss and A. Laguardia. 2006. Surviving the doctoral dissertation experience: The NW sisters' study. Journal of International Women's Studies 7(4): 168-185.

Meyer, J. H. F. 2007. On the modelling of postgraduate students' conception of research. South African Journal of Higher Education 21(8): 1103-1116.

Meyer, J. H. F., and R. Land. 2003. Threshold Concepts and Troublesome Knowledge 1: Linkages to ways of thinking and practising. In Improving student learning: Then years on, ed. C. Rust. Oxford: OCSLD.

Morton, K. R. and J. S. Worthley. 1995. Psychology Graduate Program Retention, Completion and employment outcomes. Journal of Instructional Psychology 22(4): 349.

Ngunjiri, F. W., K. C. Hernandez and H. Chang. 2010. Living autoethnography: Connecting life and research. Journal of Research Practice 6(1): Article E1. http://jrp.icaap.org/index.php/ jrp/article/view/241/186 (accessed 4 February, 2012).

Neville, B. 2008. Creating a research community. Qualitative Research Journal 8(1): 37-46.

Olivier, M. A. J. 2007. Post-graduate supervision: For better or for worse? South African Journal of Higher Education 21(8): 1126-1141.

Parker, R. 2009. A learning community approach to doctoral education in the Social Sciences. Teaching in Higher Education 14: 43-54. doi: 10.1080/13562510802602533.

Protivnak, J. J. and L. L. Foss. 2009. An exploration of themes that influence the Counsellor Education doctoral students' experience. Counsellor Education and Supervision 48(4): 239-256.

Reilly, R. C. and G. Bramwell. 2007. The use of public reflection circles and promotion of metacognition: Teaching for autonomy and good practice. Journal of Educational Enquiry 7(1): 44-63.

Samara, A. 2006. Group supervision in graduate education: A process of supervision skill development and text improvement. Higher Education Research and Development 25(2): 115-139.

Sambrook, S., J. Stewart and C. Roberts. 2008. Doctoral supervision ... a view from above, Below and the middle. Journal of Further and Higher Education 32(1): 71-84. doi: 10.1080/0398770701781473.

Van Biljon J. A. and E. de Kock. 2011. Multiplicity in supervision relationships: A factor in improving throughput success? South African Journal of Higher Education 25(5): 987-1002.

Watts, J. H. 2010. Team supervision of the doctorate: Managing roles, relationships and contradictions. Teaching in Higher Education 15(3): 335-339.

Wisker, G., G. Robinson and M. Shacham. 2007. Postgraduate research success: Communities of 
practice involving cohorts, guardian supervisors and online communities. Innovations in Education and Teaching International 44(3): 301-320. doi: 10.1080/14703290701486720.

Wisker, G., G. Robinson, V. Trafford, J. Lilly and M. Warnes. 2004. Achieving a doctorate: Metalearning and Research Development Programmes supporting success for international distance students. Innovations in Education and Teaching International 41(4): 473-489. doi: 10.1080/1470329042000277048.

Zhao, F. 2001. Post-graduate research supervision: A process of knowledge management. Centre for Management Quality Research, Bundoora West, RMIT University. ultiBASE Articles. http://ultibase.rmit.edu.au/Articles/may01/zhao1.html

Zuber-Skerritt, O. and N. Knight. 1987. Problem definition and thesis writing: Workshops for the postgraduate student. Higher Education 15(1/2): 89-103. 